\title{
Exercise motivational regulations and exercise addiction: The mediating role of passion
}

\author{
ÁLVARO SICILIA ${ }^{1 *}$, MANUEL ALCARAZ-IBÁÑEZ ${ }^{1}$, MARÍA-JESÚS LIROLA ${ }^{1}$, RAFAEL BURGUEÑO ${ }^{1}$ \\ and ANTHONY MAHER ${ }^{2}$
}

\author{
${ }^{1}$ Facultad de Ciencias de la Eduación, Universidad de Almería, Almería, Spain \\ ${ }^{2}$ Department of Sport and Physical Activity, Edge Hill University, Ormskirk, UK
}

(Received: October 27, 2017; revised manuscript received: March 1, 2018; accepted: March 31, 2018)

\begin{abstract}
Background and aims: The study explored the mediating role of forms of passion in the relationship between motivational regulations in exercise and exercise addiction (EA). Methods: A total of 485 university students (368 males and 117 females; $M_{\text {age }}=20.43, S D=3.21$ ) completed a questionnaire measuring the frequency and intensity of exercise, motivational regulations in exercise, passion for exercise, and EA. Controlling the effects of age, frequency, and intensity of practice, the relationships between the study variables were examined though a path analysis. Results: Both self-determined and non-self-determined forms of motivation showed positive association with EA. The forms of motivation with greatest predictive power for EA were introjected and integrated regulations. Both forms of motivation had positive direct and indirect effects through obsessive passion (OP) on EA; however, integrated regulation also showed negative indirect effects through harmonious passion on EA. Conclusions: Both forms of passion and, especially, OP, seem to affect how motivational regulations are associated with EA. These findings clarify the association found in previous studies between self-determined forms of motivation and EA.
\end{abstract}

Keywords: dualistic model of passion, exercise dependence, internalization, motivation, self-determination theory

\section{INTRODUCTION}

Exercise addiction (EA) is a behavioral disorder that involves exercising in a way that is repetitive, frequent, generally stereotyped, is difficult to control or decrease, and manifests in physiological (e.g., tolerance and withdrawal) and/or psychological (e.g., anxiety and depression) symptoms (Hausenblas \& Downs, 2002). Additionally, EA has been associated with physical (e.g., risky behaviors, herniated disks, and fascitis) and social (e.g., interpersonal conflicts) negative consequences (Akehurst \& Oliver, 2014; Schreiber \& Hausenblas, 2015). Research estimates that the prevalence of EA in the general population is around $3 \%-5 \%$, although this figure may be higher in specific populations, such as sport science students and longdistance runners (Sicilia \& González-Cutre, 2011; Symons Downs, Hausenblas, \& Nigg, 2004; Szabo, De la Vega, Ruiz-Barquín, \& Rivera, 2013). EA prevalence at first may seem small when compared with other addictions (Sussman, Lisha, \& Griffiths, 2011). Nonetheless, it is still significant given the negative consequences associated with this form of exercise (Berczik et al., 2012). Although EA has been studied as a behavioral addiction for the past 40 years, there is still much that remains unknown about the nature of this disorder and the factors that can cause it. This represents a significant challenge for basic and applied research, because an understanding of the etiology of EA would allow for more effective prevention and treatment.
The research has shown that motivation can be a key antecedent of EA (Edmunds, Ntoumanis, \& Duda, 2006; González-Cutre \& Sicilia, 2012b; Parastatidou, Doganis, Theodorakis, \& Vlachopoulos, 2014; Symons-Downs, Savage, \& DiNallo, 2013). Indeed, maintaining high motivation to exercise seems key to developing an excessive dedication to this behavior. However, the relationship between motivation and EA can be influenced by both the amount of an individual's motivation to engage in a particular behavior and the quality of that motivation, i.e., the intensity and direction of individual effort. Therefore, the purpose of this study was to explore the relationship between motivation and EA using self-determination theory (SDT).

\section{SDT and EA}

SDT is an organismic theory of human motivation that postulates the individual's intrinsic tendency to integrate its experiences with a coherent internal structure called self (Deci \& Ryan, 2000; Ryan \& Deci, 2017). SDT has been extensively used to explain exercise behavior (Standage \& Ryan, 2012). This theory adopts a multidimensional

\footnotetext{
* Corresponding author: Álvaro Sicilia-Camacho; Facultad de Ciencias de la Educación, Universidad de Almería, Carretera de Sacramento s/n, 04120 La Cañada de San Urbano, Almería, Spain; Phone: +34 950 0155394; Fax: +34 950 015751; E-mail: asicilia@ ual.es
}

This is an open-access article distributed under the terms of the Creative Commons Attribution-NonCommercial 4.0 International License, which permits unrestricted use, distribution, and reproduction in any medium for non-commercial purposes, provided the original author and source are credited, a link to the CC License is provided, and changes - if any - are indicated. 
perspective of motivation, focusing on intrinsic motivation, extrinsic motivation, and amotivation (Ryan \& Deci, 2017) to better understand the reasons that lead individuals to exercise and reasons that can explain EA.

The degree to which the regulation of the exercise behavior becomes internalized, i.e., the degree to which one synthesizes the social values of exercise and incorporates them into oneself, influences the forms of motivation. Here, forms of motivation can be placed on a continuum ranging from completely self-determined or autonomous (e.g., an individual engages in exercise by choice) to completely non-self-determined or controlled (e.g., an individual feels forced or pressured into exercising, either by others or by themselves).

Within SDT, the quality of motivation is determined by the amount or degree of internalization occurring. Intrinsic motivation is the most self-determined form, implying a commitment to exercise for its pleasure and satisfaction. Extrinsic motivation implies that exercise is carried out, instead, for instrumental reasons. Extrinsic motivation includes four motivational regulations that can be arranged on a continuum according to the process of behavioral internalization. Integrated regulation represents the most complete form of internalization of extrinsic motivation in which exercise is integrated into one's lifestyle and synthesized with the self. Here, the social value that the behavior represents is congruent with an individual's other values and needs. Identified regulation implies that an individual exercises because they recognize the social value attributed to that behavior. Introjected regulation implies a minimal degree of internalization where the individual is motivated by the desire to avoid internal pressure through feelings of guilt or shame. Finally, external regulation entails no internalization process, so that the individual engages in exercise either to obtain an external incentive (e.g., the acknowledgement of others) or to avoid a negative end state (e.g., an instructor's reprimands). Although these four motivational regulations represent, to differing degrees, less than fully self-determined behavior, individuals will identify with the importance of exercise, assimilate it into their sense of self, and accept it for its own value when the internalization process is fully developed. However, when the internalization process is forestalled, regulations and values associated with exercise may either remain external or be only partially internalized to form introjects or unintegrated identifications. Finally, amotivation is characterized by a lack of interest in exercising.

SDT proposes that intrinsic motivation and integrated and identified regulations are accompanied by an internal perceived locus of causality, which represents highly autonomous or self-determined forms of motivation. On the other hand, amotivation and introjected and external regulations are characterized by an external perceived locus of causality and reflect controlled or non-self-determined forms of motivation. Here, it is important to point out that this grouping does not make the processes that underlie the forms of motivation within a group (i.e., self-determined and non-self-determined) similar. Therefore, when extrinsic motivation is integrated or identified, it is still not typically transformed into intrinsic motivation because, theoretically, it retains its instrumental nature and it highlights the different processes that underlie intrinsic motivation (i.e., doing activities because they are inherently interesting and enjoyable). While processes are notably different, the degree to which an action is experienced as autonomous or self-determined is of critical importance (Ryan \& Deci, 2017). In this vein, numerous studies have shown that the most self-determined forms of motivation in exercise lead to positive consequences, such as vitality, positivity, well-being, interest, concentration, effort, satisfaction, enjoyment, and exercise adherence. In contrast, non-selfdetermined forms of motivation are associated with maladaptive consequences, such as social physique anxiety, body dissatisfaction, perceived pressure to lose weight, lower subjective vitality, anxiety, guilt, and contingent self-worth (see Standage \& Ryan, 2012).

To date, only a few studies have analyzed the relationship between the forms of motivation established by SDT and EA (Edmunds et al., 2006; Fortier \& Farrell, 2009; González-Cutre \& Sicilia, 2012b; Hamer, Karageorghis, \& Vlachopoulos, 2002; Symons-Downs et al., 2013). Although these studies indicate that introjected regulation seems to be the strongest positive predictor of EA, they also show that self-determined forms of motivation (e.g., integrated and identified regulations) usually have a positive association with EA. Therefore, the relationship between motivational regulations and EA does not appear to fully confirm the prediction of SDT, which postulates that more self-determined forms of motivation can lead to more positive consequences (i.e., healthy exercise participation), whereas non-self-determined types of motivation can lead to more negative consequences (i.e., EA). One possible explanation is that motivational regulations play a limited role in explaining this disorder (Parastatidou et al., 2014). Some studies have shown that motivations for exercise account for only $15 \%$ of the total variance in EA score (Hamer et al., 2002). Thus, there is room for other motivational factors to potentially influence EA. Passion has been proposed as one of these factors (González-Cutre \& Sicilia, 2012b; Parastatidou et al., 2014). If individuals are passionate about exercise, it is very likely that they feel highly motivated to engage in such behavior; however, forms of exercise motivation could lead to excessive exercise engagement depending on the ways in which that passion manifests. Therefore, the relationship between motivation and EA can be influenced both by the presence of passion and the type of passion that leads the individual to exercise.

\section{The role of passion for exercise}

Vallerand et al. (2003) have proposed a theoretical structure of passion, which focuses on the motivational process that involves intense and persistent participation in an activity (see also Vallerand, 2008, 2010, 2012, 2015). These authors define passion as "a strong inclination toward an activity that people like, that they find important, and in which they invest time and energy" (Vallerand et al., 2003, p. 757). Based on the principles of SDT, the dualistic model of passion (DMP) posits that there are two types of passion, each characterized by a specific form of activity engagement. Here, harmonious passion (HP) reflects an autonomous internalization of behavior, whereas obsessive 
passion (OP) manifests as a controlled internalization of activity within one's own identity.

Building on DMP, it is proposed that when individuals have HP for exercise, they will tend to express a strong desire to engage in it and will voluntarily integrate it as a significant part of their identity, but not so much that it will become overwhelming. For example, a student who presents an HP for exercise will have a strong desire for doing exercise but will be able to postpone training to concentrate on preparation for an imminent university exam. Thus, with $\mathrm{HP}$, individuals will control their exercise and decide when to and when not to exercise, so that they can integrate exercise in a manner that is consistent and compatible with the other domains of their life. Conversely, when individuals have OP for exercise, they feel a strong desire to do it. This behavior is difficult to control, so people experience difficulty in regulating and integrating exercise into other domains of life. This can produce conflicts within other aspects of the individual's life (e.g., academic life, family life, and the relationship with their partner) and have negative consequences (e.g., negative affect and rumination) both during and after exercise (Vallerand, 2010, 2015; Vallerand et al., 2003).

Passion is a motivational construct also based on SDT. However, while SDT considers different degrees of internalization that are the basis of forms of motivation, DMP is related to the manner in which this process happens (Vallerand, 2010, 2015). In this vein, DMP makes a distinction on the quality of the internalization by separating a harmonious manner to internalize activities (i.e., when internalized elements are coherently organized among themselves and are not in conflict) from an obsessive manner (i.e., when the process perturbs the inherent harmony among selfelements and creates conflict among internalized elements). Therefore, an individual's passion for an activity (e.g., exercise) implies a certain amount of internalization, given that the activity is configured as one of, if not the, central components of his/her identity (e.g., an athlete). However, the cognitive, emotional, and behavioral consequences of the internalization process could vary widely depending on the quality of that process, i.e., on the autonomous or controlled nature with which it occurs. Given that EA might emerge from a combination of motivational regulations, the passion construct can help us to understand the mediating process within the relationship between forms of motivation and EA. In other words, passion encapsulates a love for the activity (i.e., intrinsic motivation), differentiated by whether it is internalized fully (i.e., HP) or only partially, with contingencies attached (i.e., OP). Therefore, both passions encapsulate some intrinsic interest but are differentiated by what this interest is combined with.

Research has shown that having OP can be a precursor to addiction to leisure activities (Curran, Hill, Appleton, Vallerand, \& Standage, 2015; Vallerand, 2010, 2015), including exercise (Akehurst \& Oliver, 2014; Paradis, Cooke, Martin, \& Hall, 2013). However, Parastatidou et al. (2014) demonstrated that passion served a mediating role in the relationship between the types of motivation established by SDT and EA. The results of the study by Parastatidou et al. suggested that OP mediated the positive effect of introjected regulation on EA. Nonetheless, these results do not exclude the possibility that the two forms of passion can mediate the effect of other types of motivational regulation on EA. In fact, consideration of DMP reveals the plausibility that regulations involving a high degree of internalization of an activity can have some effect on EA if this occurs in an obsessive way. In this vein, studies that have analyzed EA considering all types of motivational regulation proposed by SDT have found that integrated regulation maintains a stronger positive association with EA to a level similar to introjected regulation (see GonzálezCutre \& Sicilia, 2012a; Symons-Downs et al., 2013). These results suggest that under SDT, integrated regulation can contribute to the appearance of consequences associated with an individual's proper functioning and overall wellbeing. There is also a possibility that the positive or negative nature of these consequences is determined by how individuals integrate exercise into their own identity. Thus, the autonomous and harmonious integration of exercise can lead to a positive result (i.e., less risk of EA), whereas integrating this activity in a controlled and obsessive way could lead to a negative result (i.e., an increased risk of EA). This possibility also makes sense when considering that feeling passion for exercise involves the presence of a high degree of internalization because representations of an activity that one enjoys and engages in are incorporated into an individual's identity (Vallerand et al., 2003). Nevertheless, although the distinct nature of the internalization process implicit in forms of passion could be the key element explaining the influence that integrated regulation can have on EA, Parastatidou et al. (2014) did not consider the extent of integrated regulation. This hypothesis has not yet been tested.

\section{The present study}

This study's objective was to use all forms of motivation recognized by SDT to examine whether HP and OP for exercise mediated the association between motivational regulations and EA. Furthermore, this study considered two measures of EA that respond to different conceptual models of this disorder: (a) the Exercise Dependence Scale Revised (EDS-R), an instrument that conceptualizes and operationalizes EA based on symptoms of substance dependence as stated in the the fourth edition of Diagnostic and Statistical Manual of Mental Disorders (DSM; American Psychiatric Association [APA], 1994) and (b) EA Inventory (EAI), which conceptualizes this disorder based on behavioral addiction, in line with the classification stated in the fifth edition of DSM (APA, 2013). Previous studies explored the (direct or mediated) relationship between the forms of motivation and EA (e.g., Edmunds, Ntoumanis, \& Duda, 2007; Fortier \& Farrell, 2009; González-Cutre \& Sicilia, 2012b; Hamer et al., 2002; Symons-Downs et al., 2013) through the use of various instruments. However, the results of these studies are not conclusive. Therefore, this study makes a relevant contribution to the body of knowledge relating to this field of research.

According to previous research, it was hypothesized that although introjected and integrated regulations would be the strongest positive predictors of EA, these effects would be mediated by passion for exercise. Specifically, it was 
hypothesized that forms of motivation that involve the internalization of exercise behavior would positively predict EA when this relationship was mediated by OP. In fact, OP has been positively associated with pathological behaviors, such as reducing other activities and rigidly continuing the favored activity (Vallerand, 2010; Vallerand et al., 2003; Vallerand \& Verner-Filion, 2013). Therefore, individuals displaying OP for exercise will tend to show higher levels of EA. Conversely, it was hypothesized that HP would negatively mediate the association between motivation and EA. HP has been associated with both flexible involvement in an activity and the presence of situational positive affect (Vallerand, 2010). Thus, internalizing exercise behavior in a harmonious manner could reduce the risk of developing EA.

\section{METHODS}

\section{Participants}

Participants were 485 university students (368 males and 117 females) who reported being currently involved in exercise. About 28\% of the participants exercised 2-3 times per week, 52\% exercised 4-5 times per week, and the remaining 20\% exercised 6-7 times per week. The ages of the participants ranged between 17 and 44 years $\left(M_{\text {age }}=\right.$ $20.43, S D=3.21)$. According to the scores on the EAI, and following criteria established by Mónok et al. (2012), 10.9\% of the participants were considered as asymptomatic, $76.1 \%$ as symptomatic but not dependent, and $13 \%$ as at risk of addiction. Meanwhile, according to the criteria established by Symons Downs et al. (2004) for the EDS-R, these percentages among the participants were $9.5 \%, 86.4 \%$, and $6.4 \%$, respectively.

\section{Measures}

Frequency and intensity of physical exercise. The participants reported the number of days per week that they usually exercised for at least $15 \mathrm{~min}$. In addition, they subjectively self-assessed whether the intensity of their physical exercise was low, medium, or high, according to a definition established by Godin and Shephard (1985).

Motivational regulations. The Spanish version (GonzálezCutre, Sicilia, \& Fernández, 2010) of the Behavioral Regulation in Exercise Questionnaire (BREQ-2; Markland \& Tobin, 2004) was used. The instrument was headed with the statement "Why do you engage in exercise?" and consisted of 23 items: 4 for intrinsic motivation (e.g., "I exercise because it's fun"), 4 for integrated regulation (e.g., "I exercise because it is consistent with my life goals"), 3 for identified regulation (e.g., "I value the benefits of exercise"), 4 for introjected regulation (e.g., "I feel guilty when I don't exercise"), 4 for external regulation (e.g., "I exercise because other people say I should"), and 4 for amotivation (e.g., "I don't see why I should have to exercise"). Participants scored responses on a Likert-type scale ranging from 0 (not true for me) to 4 (very true for me).

Passion for exercise. The Spanish adaptation (AlcarazIbáñez, Sicilia, Lirola, \& Burgueño, 2016) of the Passion
Scale in Exercise (Parastatidou, Doganis, Theodorakis, \& Vlachopoulos, 2012) was used. This instrument consists of 14 items grouped into two subscales of seven items that assess the degree of HP (e.g., "exercise I do is in harmony with the other activities in my life") and OP (e.g., "I cannot live without exercise") for exercise. For the responses, a Likert-type scale ranging between 1 (totally disagree) and 7 (totally agree) was used.

Exercise addiction (EA). This variable was assessed through two different measures. First, the Spanish version (Sicilia, Alías-García, Ferriz, \& Moreno-Murcia, 2013) of EAI (Terry, Szabo, \& Griffiths, 2004) was used. The scale consists of six items (e.g., "if I have to miss an exercise session I feel moody and irritable") grouped into a single factor. The sentence that preceded the scale was "To what degree do you agree with the following statements ... ?" For the response, participants used a Likert scale that ranged between 1 (totally disagree) and 5 (totally agree). Second, the Spanish version (Sicilia \& González-Cutre, 2011) of the EDS-R (Symons Downs et al., 2004) was utilized. The scale consists of seven factors over 21 items (e.g., "I would rather exercise than spend time with family/friends"), providing an overall score of dependence (higher levels indicate an increased risk of dependence). The sentence that preceded the scale was "To what degree are the following statements true for you?" For the response, a Likert-type scale that ranged between 1 (never) and 6 (always) was used.

\section{Procedure}

Two Spanish universities were contacted to recruit participants for this study. The questionnaire was administered in the presence of one of the authors, who informed the participants of the aim and purpose of the study and the voluntary nature of their participation. The researcher was available to the participants to answer any questions that they could arise during the data-collection process. The approximate time to complete the questionnaire was $20 \mathrm{~min}$.

\section{Statistical analysis}

First, preliminary analyses were performed and both the existence of outliers and compliance with the requirements of applying multivariate statistical techniques was verified. Around 10 cases $(|z|>4.00, p<.001)$ were considered as univariate outliers (Hair, Black, Babin, Anderson, \& Tatham, 2006). About four cases exceeded the Mahalanobis distance $\left(D^{2}\right)$ critical value of 34.91 corresponding to the $\chi^{2}$ test $(d f=12, p<.001)$, so these were considered as multivariate outliers. The removal of these 14 cases led to the final sample used in subsequent analyses $(N=485)$. Descriptive statistics and bivariate correlations were computed, using the Pearson's coefficient $(R)$ in the latter case. Estimates of internal consistency were computed for each subscale using a composite reliability index ( $\rho$; Raykov, 2004) derived from the results of the confirmatory factor analyses (CFAs) conducted in Mplus 7 (Muthén \& Muthén, 1998-2015). Given the ordinal polytomous character of the items comprising the factors, these CFA were conducted using the robust weighted least square adjusted by mean and variance estimation method. Furthermore, to determine the 
possible effects of gender on EA scores, a Student's $t$-test for independent samples was performed.

Next, structural equation modeling (SEM) technique using observed variables (i.e., path analysis) was employed to investigate if harmonious and OP mediated the relationship between forms of motivation and EA. This technique was adopted because latent variables would have implied the presence of very low ratio of cases to free parameters. To avoid a spurious inflation of indirect effects (Hayes, 2013), the full saturated model displayed in Figure 1 was tested using the maximum likelihood estimation method and a bootstrapping technique in Mplus 7 (Muthén \& Muthén, 1998-2015). Applying 10,000 bootstrap resamples, the standard errors and $95 \%$ confidence interval (CI) of the direct, indirect, and total effects of each form of motivational regulation on EA were obtained. CI indicated the presence of a statistically significant effect if it does not contain zero. This method provides a more accurate estimate of indirect effects than the normal theory-based Sobel Test and does not require the sample to be normally distributed (Hayes, 2013). Frequency, intensity of practice (Symons Downs et al., 2004), and age (González-Cutre \& Sicilia, 2012b) were introduced as covariates in the model. A $p<.05$ level of significance was used for all statistics.

\section{Ethics}

The ethical board of Universidad de Almería approved this research. All subjects were informed about the study and all provided informed consent.

\section{RESULTS}

\section{Preliminary analyses}

Table 1 presents the means, standard deviations, and bivariate correlations of the variables, along with the coefficients of internal consistency of the different scales [At the request of an anonymous reviewer, we conducted a CFA testing a bifactor exploratory structural equation modeling (ESEM) structure previously proposed for instruments intended to measure motivational regulations from the perspective of SDT (Howard, Gagné, \& Bureau, 2017). Despite adequate goodness-of-fit indexes being obtained, items belonging to intrinsic and integrated motivation specific factors showed lower loadings in the general factor than items from a less self-determined specific factor, such as identified regulation. Additionally, up to six items showed factor loadings in their correspondent specific factors below 0.30. Given the inconclusive results of this analysis, and in absence of previous evidence supporting the bifactor ESEM structure for the BREQ-3, we opted for relying on the six correlated factor structure.]. The scores of self-determined forms of motivation (i.e., intrinsic motivation and integrated and identified regulations) were above the midpoint of the respective scales, whereas non-self-determined forms of motivation (i.e., introjected and external regulation and amotivation) were below the midpoint. The scores found for HP were higher than those found for OP, with both cases being above the midpoint on the scales. The indices of internal consistency of the instruments were above the cut-off point of 0.70 . All the variables correlated positively with EA, showing intensities that ranged from weak to moderate. The Student's $t$-test for independent samples did not show statistically significant differences between males and females on EA scores obtained both by EAI $[t(483)=0.019, p=.80]$ and EDS-R $[t(483)=0.026, p=.75]$.

\section{Structural equation model}

The results of the path analysis model (Table 2, Figure 2) show that when the effects of age, frequency, and intensity of practice are controlled for, intrinsic motivation and integrated regulation predicted HP in a positive and statistically significant way. The results indicate that HP mediated, in a negative and statistically significant way, the existing relationship between (a) integrated regulation and EA and
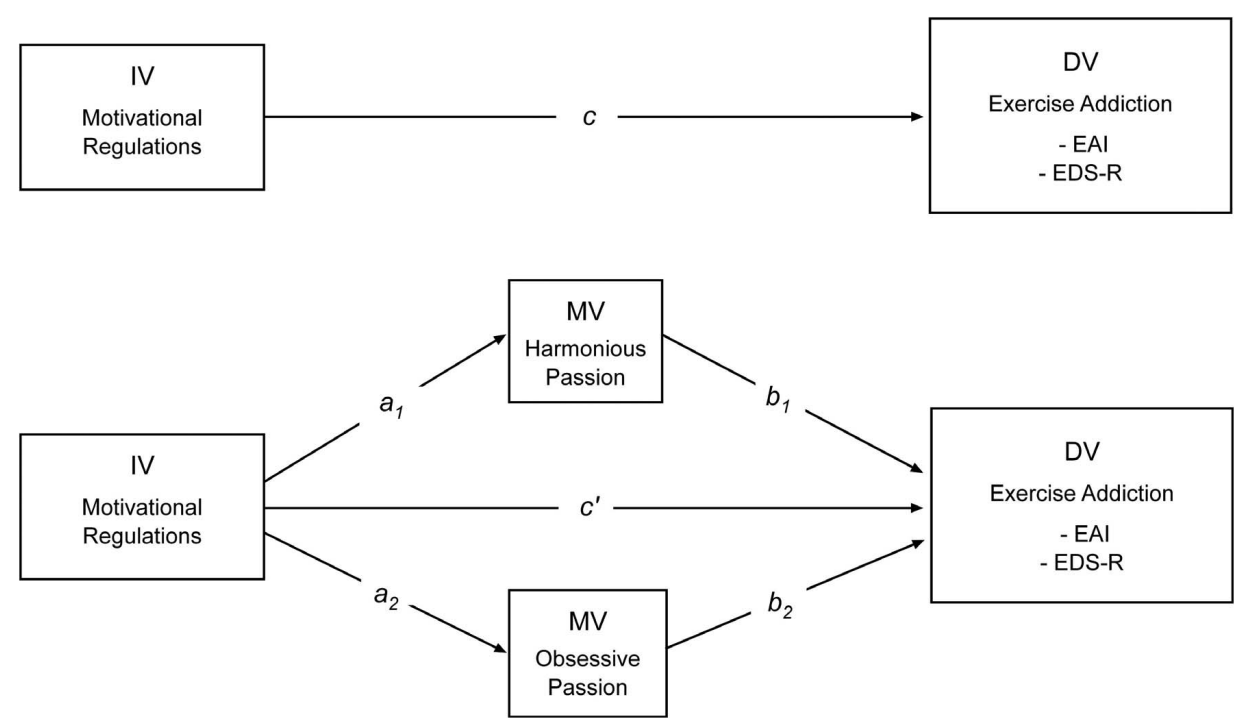

Figure 1. Hypothesized multiple mediation model. Note. IV: independent variable; MV: mediator variable; DV: dependent variable; $c^{\prime}$ : direct effect; $c$ : total effect $\left[\left(a_{1} b_{1}\right)+\left(a_{2} b_{2}\right)+c^{\prime}\right]$ 


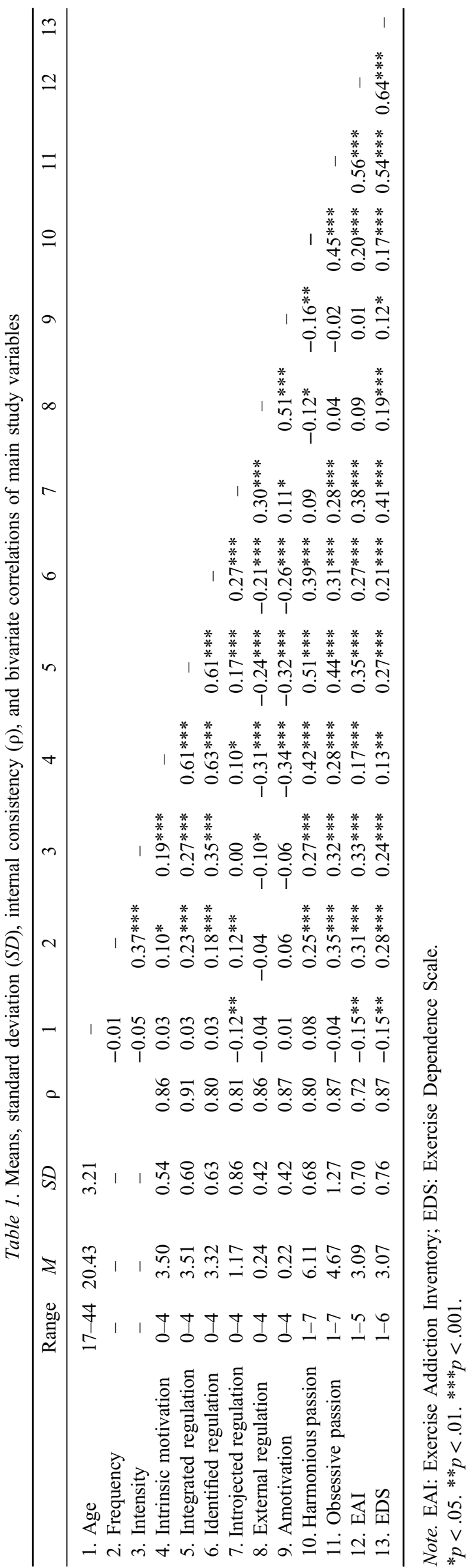

(b) to a lesser extent, intrinsic motivation and EA, in both cases measured with EAI and EDS-R. In contrast, OP mediated, in a positive and statistically significant way, the existing relationship between (a) integrated regulation and EA and (b) introjected regulation and EA, in both cases measured with EAI and EDS-R. Overall, the independent variables explained $32 \%$ of HP, $33 \%$ of OP, and $41 \%$ of EA, measured with EAI and EDS-R.

\section{DISCUSSION}

The study explored the mediating role of forms of passion in the relationship between motivational regulations in exercise and EA. It was hypothesized that motivation would be positively associated with EA when this relationship was mediated by OP, whereas this association would be negative when mediated by HP. This is because OP implies a controlled internalization that breeds an internal compulsion to engage in exercise, leading to a more rigid and conflicted form of activity involvement (Vallerand, 2010). On the other hand, HP implies an autonomous internalization of the activity, leading the individual to engage in exercise in a more flexible manner (Vallerand, 2012, 2015; Vallerand et al., 2003). This study represents an improvement upon previous research that explored the relationship between the forms of motivation considered by SDT and EA (Edmunds et al., 2007; Fortier \& Farrell, 2009; Hamer et al., 2002; Parastatidou et al., 2014), because it simultaneously includes measures of integrated regulation and a mediation analysis that enables a more precise identification of the motivational process underpinning EA. Moreover, given the existing controversy around symptoms that may underlie this behavioral disorder (Sussman \& Sussman, 2011), the study confirms this relationship considering two different measures of EA (i.e., EDS-R and EAI). The proposed hypotheses were partially confirmed. The results showed that not only did non-self-determined forms of motivation (i.e., introjected regulation) positively predict EA through the mediation of OP, but also the association between forms of self-determined motivation (i.e., integrated regulation) and EA remained positive when this relationship was mediated by OP. Conversely, but to a lesser extent, selfdetermined forms of motivation (i.e., integrated and intrinsic regulation) had negative predicting effects on EA through the mediation of HP. Therefore, results of this study suggest that engaging in exercise out of love and considering this activity an important part of your self does not necessarily lead to adaptive outcomes (e.g., a healthy exercise participation), because it depends on what type of passion for exercise is displayed.

Considering the relationship between forms of motivation and EA, our results showed moderate positive correlations of EA, not only with non-self-determined forms of motivation (i.e., introjected regulation) but also with forms of self-determined motivation (especially integrated regulation). These results are in line with previous studies that have analyzed the relationship between forms of motivation from SDT and EA (Fortier \& Farrell, 2009; González-Cutre \& Sicilia, 2012b; Hamer et al., 2002; Symons-Downs et al., 2013). At first glance, the positive association found in this 
Sicilia et al.

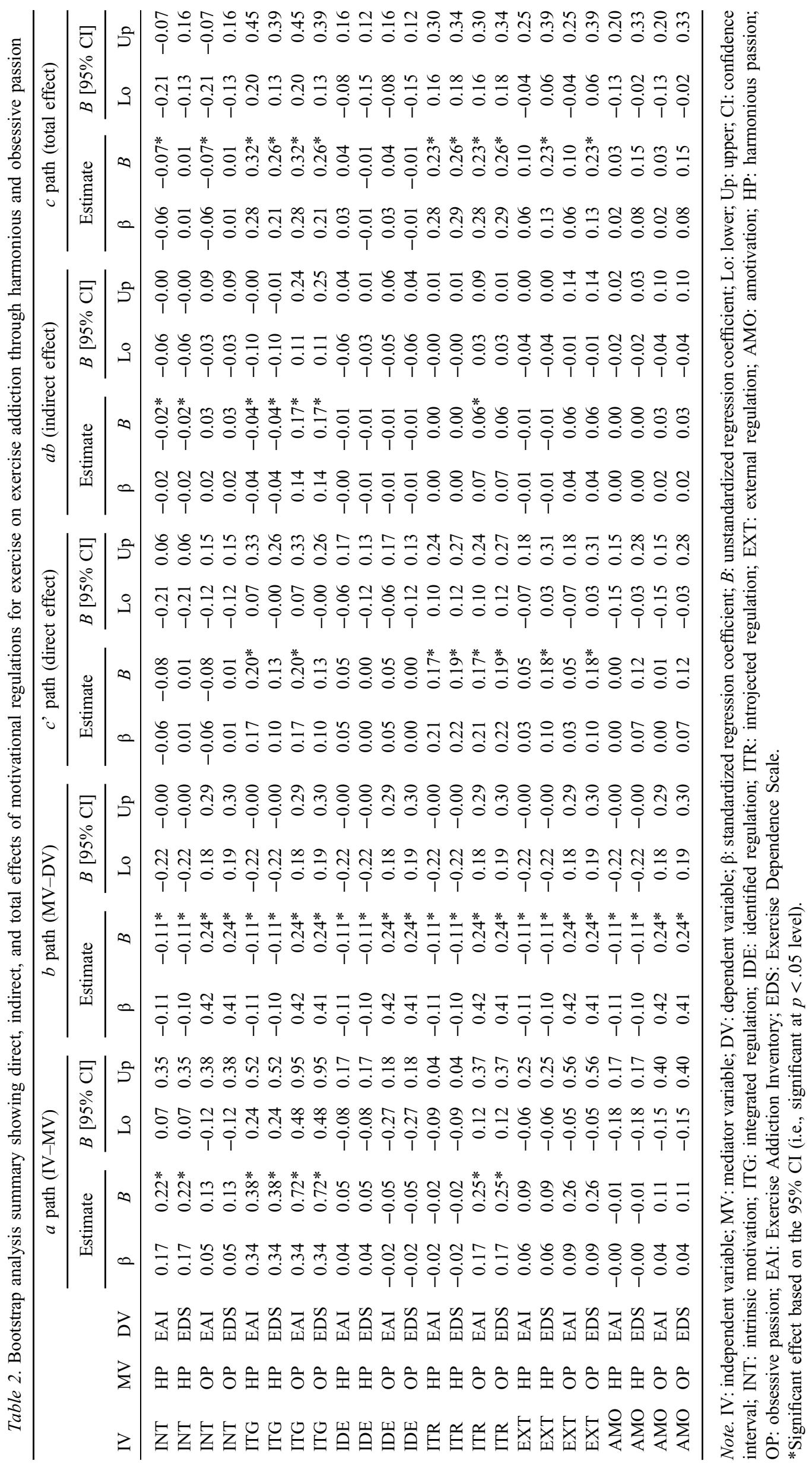




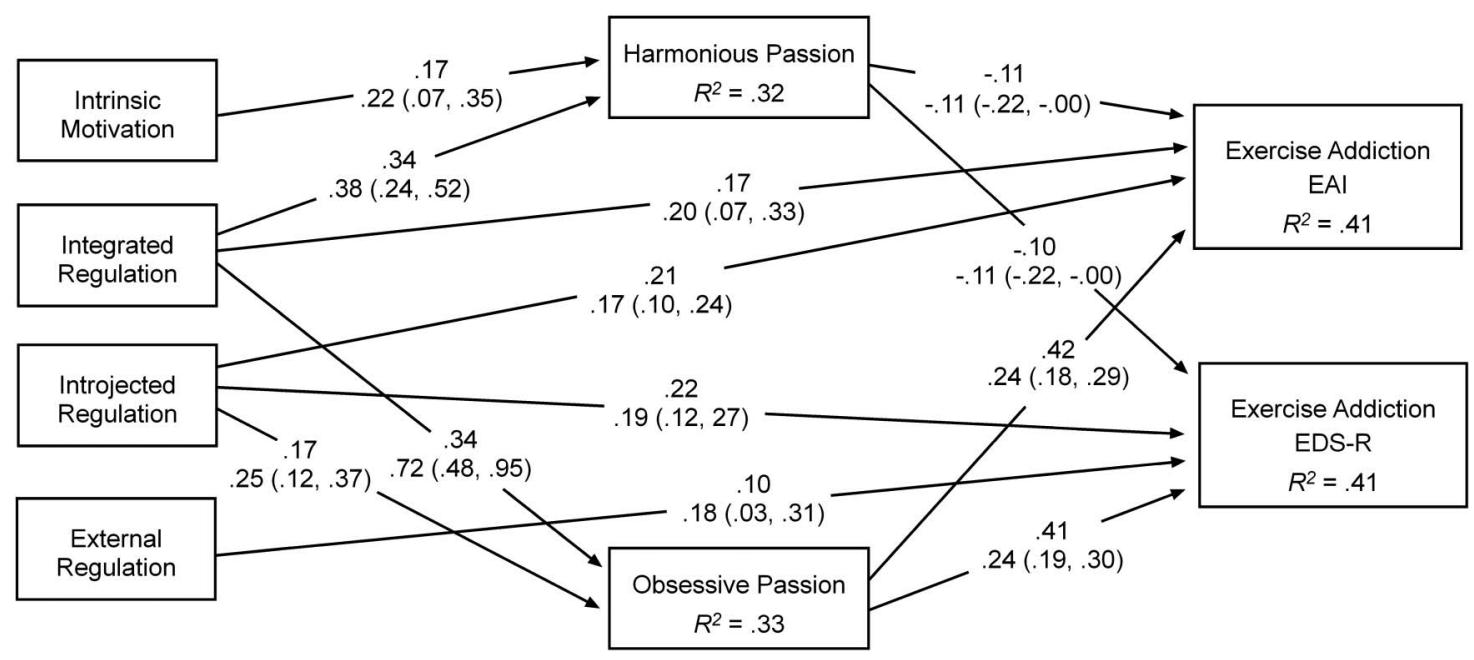

Figure 2. Harmonious and obsessive passion as mediators of the relationship between motivational regulations and exercise addiction. Due to clarity reasons, only statistically significant paths are shown. All specific indirect effects through harmonious and obsessive passion are significant. Values in the upper row signify unstandardized regression coefficients, while values in the lower row represent standardized regression coefficients followed by $95 \%$ confidence interval in brackets

and other studies between the forms of self-determined motivation and EA do not appear consistent with the principles of SDT, which proposes that self-determined forms of motivation should have positive consequences (i.e., healthy exercise). However, it is unsurprising that integrated regulation was not only the form of self-determined motivation that had a greater positive association with EA, but also shown to be a positive predictor of EA. In this form of regulation, individuals both value and integrate exercise into their identity. Furthermore, as hypothesized in this study, a high degree of exercise behavior internalization does not necessarily determine the quality of that process, i.e., how individuals integrate that behavior into their identity. As our results suggest, considering this latter aspect could clarify the positive association found in past studies between self-determined forms of motivation and EA. Indeed, the results of the correlation analysis in this study show that although self-determined forms of motivation (i.e., intrinsic motivation and integrated and identified regulations) maintained a stronger positive association with HP than with OP, both associations showed moderate coefficients. Therefore, the association of self-determined forms of motivation with the two types of passion is consistent with DMP because, in both forms, individuals value the activity and consider it as part of their own identity (Vallerand, 2015; Vallerand et al., 2003). Thus, a high degree of internalization of the values of exercise may be associated with HP if the process of internalization is developed completely and harmoniously; however, it is also possible to find self-determined forms of motivation in exercise and maintain OP for this activity.

The results of the mediation analysis suggest that the effects of integrated and introjected regulations on EA were partially mediated by the types of passion for exercise in such a way that motivational regulations were shown as distal precursors related to EA (Shrout \& Bolger, 2002). Furthermore, these results suggest that the manner in which each form of passion mediated the relationship was clearly different. Whereas OP had positive and statistically significant effects on EA, HP had, albeit to a lesser extent, negative and statistically significant effects on EA. This is in line with previous research (Akehurst \& Oliver, 2014; Paradis et al., 2013) and DMP (Vallerand, 2010, 2015). Thus, the results of this study show that introjected regulation positively predicted EA not only directly, but also through the mediating role of OP. These results are consistent with the previous study by Parastatidou et al. (2014) and suggest that individuals who develop a sense of guilt if they are unable to exercise are likely to reflect a rigid persistence toward the activity. When this happens, it can become difficult to balance exercise with other domains in life, which can lead to the manifestation of greater EA symptoms (Vallerand \& Verner-Filion, 2013). However, this study's results are novel, i.e., they show that self-determined forms of motivation (i.e., integrated regulation) can have both positive and negative indirect effects (in addition to direct positive effects) on EA, depending on the mediating effect of passion. These results partially support the hypothesis proposed in this study and contribute to explaining the results in the literature that positively associate EA with forms of self-determined motivation (e.g., Edmunds et al., 2006; Fortier \& Farrell, 2009; González-Cutre \& Sicilia, 2012a; Hamer et al., 2002). Indeed, the results suggest that when explaining the relationship between motivational factors in exercise and the behavioral disorder that EA represents, it seems wise to consider not only the degree of internalization, but also the quality of that process, i.e., how individuals integrate a behavior into their identity.

Apart from the effect of introjected and integrated regulations, other forms of motivation had effects, although to a lesser extent, on EA. On the one hand, external regulation showed a direct and statistically significant positive effect on EA measured with EDS-R. This result supports the studies by González-Cutre and Sicilia (2012a) and Symons-Downs et al. (2013) and suggests that in the first phase, EA can be seen as encouraged by others' recognition and appreciation without the need for the individual to show passion for the activity. Therefore, this result seems 
consistent with the idea that passion, in this case for exercise, is difficult to develop with a lack of internalization (Vallerand, 2015).

In addition, the results showed that intrinsic motivation had an indirect negative effect on EA, measured with EAI and EDS-R, through mediation from HP. This association is understandable if we consider that developing HP for an activity facilitates positive intrapersonal outcomes (Curran et al., 2015; Vallerand \& Verner-Filion, 2013), which would seem appropriate when one is involved in exercise for pleasure and enjoyment (Vallerand, 2010). Thus, the positive affect experienced during exercise would facilitate an autonomous internalization of the behavior that would allow the individual to engage in the activity in a more flexible manner and thus experience fewer symptoms of addiction (Vallerand et al., 2003).

The results of this study have several implications. The negative association between HP and EA, and the positive association between OP and EA, not only support the notion that the two types of passion function differently (Vallerand, 2010, 2015; Vallerand, \& Verner-Filion, 2013), but also suggest that they can affect the relationship between motivation and EA. Therefore, the results suggest that individuals who show a high degree of internalization of exercise behavior can have symptoms of addiction if this internalization occurs in an obsessive manner. In other words, whether individuals will benefit from a high degree of internalization of exercise behavior depends on their type of passion, which will define the quality of that internalization process. These results remain fairly stable in two different measures of EA and show that the consequence of regulatory style depends not only on the amount of behavior internalization, but also on its quality, i.e., if passion for that activity is either obsessive or harmonious. With HP, the person can decide when to and when not to engage in exercise, and is able to regulate activity engagement in light of external cues. This is not the case with OP. Typically, because obsessive exercise has taken control of the person, it is done with rigid persistence, which can reduce the time to do other activities in other domains of their life (Vallerand et al., 2003). Therefore, the results suggest that the type of passion matters with respect to the relationship between the type of motivation and EA.

The findings also build on previous research (Parastatidou et al., 2014) wherein non-self-determined forms of motivation (i.e., introjected regulation) are associated with EA and, perhaps more significantly, the self-determined forms of motivation can have a positive association with EA when the manner of internalizing the behavior occurs in an obsessive way. In this vein, this study provides a partial explanation as to why self-determined forms of motivation might be associated with EA. This study supports DMP and its integration with SDT (Vallerand, 2010, 2012, 2015; Vallerand et al., 2003). Thus, introducing the concept of passion for exercise within the motivational process that could lead to EA is of interest, because it enables understanding of how individuals internalize exercise behavior into their identity.

Despite the evidence found in this study, some limitations must be highlighted. First, it should be noted that participants in this study included a convenient sample of university students pursuing a degree in physical activity and sports science. Accordingly, the associations analyzed in this study should be examined in more diverse populations. Second, this study is cross-sectional and therefore represents only a snapshot of the association between the variables. Longitudinal studies should be conducted to capture the dynamic nature of the motivational and addictive process of exercise. As previous studies have established, EA is not something that happens from one day to the next; instead, it represents a prolonged process in which regulatory motivation plays an important role (Sussman \& Sussman, 2011). Third, despite the relatively high reliability of the instruments employed in this study, we may have attenuated the inherent bias arising from the use of observed rather than latent variables in SEM. This approach may have led to an underestimation of the structural path coefficients (Stephenson \& Holbert, 2003). Finally, this study has considered two global measures of EA. Although the results have been quite stable along these two measures, some of the weakest relationships found have been observed in one of the measures. For example, external regulation showed a direct and positive predictive effect for EA measured with EDS-R, whereas this effect was no longer statistically significant and was of lesser magnitude with EAI. Future research could analyze the common and dissimilar symptoms in the conceptualization that guides different measures of EA. This approach would facilitate the interpretation of the results when a range of instruments are utilized to measure EA.

Funding sources: This research was supported by the Spanish Ministry of Education, Culture, and Sport (FPU-MED).

Authors' contribution: AS contributed to study concept and design. AS and M-JL obtained funding. AS, MA-I, M-JL, $\mathrm{RB}$, and $\mathrm{AM}$ contributed to analysis and interpretation of data, drafts review, and study supervision. AS, MA-I, and $\mathrm{RB}$ contributed to statistical analysis.

Conflict of interest: The authors declare no conflict of interest.

\section{REFERENCES}

Akehurst, S. A., \& Oliver, E. J. (2014). Obsessive passion: A dependency associated with injury-related risky behaviour in dancers. Journal of Sports Sciences, 32(3), 259-267. doi:10.1080/02640414.2013.823223

Alcaraz-Ibáñez, M., Sicilia, A., Lirola, M. J., \& Burgueño, R. (2016). Efectos de la satisfacción y frustración de las necesidades psicológicas básicas sobre las formas de pasión por el ejercicio [Effects of satisfaction and thwarting of basic psychological needs on the forms of passion for exercise]. Psychology, Society, \& Education, 8(3), 257-272. doi:10.25115/ psye.v8i3.188

American Psychiatric Association [APA]. (1994). Diagnostic and statistical manual of mental disorders (4th ed.). Washington, DC: American Psychiatric Association. 
American Psychiatric Association [APA]. (2013). Diagnostic and statistical manual of mental disorders (5th ed.). Arlington, VA: American Psychiatric Association.

Berczik, K., Szabo, A., Griffiths, M. D., Kurimay, T., Kun, B., Urbán, R., \& Demetrovics, Z. (2012). Exercise addiction: Symptoms, diagnosis, epidemiology, and etiology. Substance Use \& Misuse, 47(4), 403-417. doi:10.3109/10826084.2011.639120

Curran, T., Hill, A. P., Appleton, P. R., Vallerand, R. J., \& Standage, M. (2015). The psychology of passion: A metaanalytical review of a decade of research on intrapersonal outcomes. Motivation and Emotion, 39(5), 631-655. doi:10.1007/s11031-015-9503-0

Deci, E. L., \& Ryan, R. M. (2000). The "what" and "why" of goal pursuits: Human needs and the self-determination of behavior. Psychological Inquiry, 11(4), 227-268. doi:10.1207/ S15327965PLI1104_01

Edmunds, J., Ntoumanis, N., \& Duda, J. L. (2006). Examining exercise dependence symptomatology from a selfdetermination perspective. Journal of Health Psychology, 11(6), 887-903. doi:10.1177/1359105306069091

Edmunds, J., Ntoumanis, N., \& Duda, J. L. D. (2007). Understanding exercise adherence and psychological well-being from a selfdetermination theory perspective among a cohort of obese patients referred to an exercise on prescription scheme. Psychology of Sport \& Exercise, 8(5), 722-740. doi:10.1016/j.psychsport.2006.07.006

Fortier, M. S., \& Farrell, R. J. (2009). Comparing selfdetermination and body image between excessive and healthy exercisers. Hellenic Journal of Psychology, 6, 223-243.

Godin, G., \& Shephard, R. J. (1985). A simple method to assess exercise behavior in the community. Canadian Journal of Applied Sport Sciences, 10(3), 141-146.

González-Cutre, D., \& Sicilia, A. (2012a). Dependencia del ejercicio físico en usuarios españoles de centros de acondicionamiento físico (fitness): diferencias según el sexo, la edad y las actividades practicadas [Exercise dependence in Spanish users of fitness centres: Differences according to gender, age and practiced activities]. Behavioral Psychology, 20(2), 349-364.

González-Cutre, D., \& Sicilia, A. (2012b). Motivation and exercise dependence: A study based on self-determination theory. Research Quarterly for Exercise and Sport, 83(2), 318-329. doi:10.1080/02701367.2012.10599863

González-Cutre, D., Sicilia, A., \& Fernández, A. (2010). Hacia una mayor comprensión de la motivación en el ejercicio físico: medición de la regulación integrada en el contexto español [Toward a deeper understanding of exercise motivation: Measurement of integrated regulation]. Psicothema, 22(4), 841-847.

Hair, J. F., Black, B., Babin, B. J., Anderson, R. E., \& Tatham, R. L. (2006). Multivariate data analysis (7th ed.). Upper Saddle River, NJ: Pearson Prentice Hall.

Hamer, M., Karageorghis, C. I., \& Vlachopoulos, S. P. (2002). Motives for exercise participation as predictors of exercise dependence among endurance athletes. Journal of Sports Medicine and Physical Fitness, 42, 233-238.

Hausenblas, H. A., \& Downs, D. S. (2002). Exercise dependence: A systematic review. Psychology of Sport and Exercise, 3(2), 89-123. doi:10.1016/S1469-0292(00)00015-7

Hayes, A. F. (2013). Introduction to mediation, moderation, and conditional process analysis: A regression-based approach. New York, NY: Guilford Press.
Howard, J. L., Gagné, M., \& Bureau, J. S. (2017). Testing a continuum structure of self-determined motivation: A meta-analysis. Psychological Bulletin, 143(12), 1346-1377. doi:10.1037/bul0000125

Markland, D., \& Tobin, V. J. (2004). A modification of the Behavioral Regulation in Exercise Questionnaire to include an assessment of amotivation. Journal of Sport and Exercise Psychology, 26(2), 191-196. doi:10.1123/jsep.26.2.191

Mónok, K., Berczik, K., Urbán, R., Szabo, A., Griffiths, M. D., Farkas, J., Magi, A., Eisinger, A., Kurimay, T., Kökönyei, G., Kun, B., Paksi, B., \& Demetrovics, Z. (2012). Psychometric properties and concurrent validity of two exercise addiction measures: A population wide study. Psychology of Sport and Exercise, 13(6), 739-746. doi:10.1016/j.psychsport. 2012.06.003

Muthén, L. K., \& Muthén, B. O. (1998-2015). Mplus Version 7: User's guide (7th ed.). Los Angeles, CA: Muthén \& Muthén.

Paradis, K. F., Cooke, L. M., Martin, L. J., \& Hall, C. R. (2013). Too much of a good thing? Examining the relationship between passion for exercise and exercise dependence. Psychology of Sport \& Exercise, 14(4), 493-500. doi:10.1016/j. psychsport.2013.02.003

Parastatidou, I. S., Doganis, G., Theodorakis, Y., \& Vlachopoulos, S. P. (2012). Exercising with passion: Initial validation of the Passion Scale in Exercise. Measurement in Physical Education and Exercise Science, 16(2), 119-134. doi:10.1080/ 1091367x.2012.657561

Parastatidou, I. S., Doganis, G., Theodorakis, Y., \& Vlachopoulos, S. P. (2014). The mediating role of passion in the relationship of exercise motivational regulations with exercise dependence symptoms. International Journal of Mental Health and Addiction, 12(4), 406-419. doi:10.1007/s11469-013-9466-x

Raykov, T. (2004). Behavioral scale reliability and measurement invariance evaluation using latent variable modeling. Behavior Therapy, 35(2), 299-331. doi:10.1016/S00057894(04)80041-8

Ryan, R. M., \& Deci, E. L. (2017). Self-determination theory. Basic psychological needs in motivation, development, and wellness. New York, NY: The Guildford Press.

Schreiber, K., \& Hausenblas, H. A. (2015). The truth about the exercise addiction. Understanding the dark side of thinspiration. Lanham, MD: Rowman \& Littlefield.

Shrout, P. E., \& Bolger, N. (2002). Mediation in experimental and nonexperimental studies: New procedures and recommendations. Psychological Methods, 7(4), 422-445. doi:10.1037// 1082-989x.7.4.422

Sicilia, A., Alías-García, A., Ferriz, R., \& Moreno-Murcia, J. A. (2013). Spanish adaptation and validation of the Exercise Addiction Inventory (EAI). Psicothema, 25(3), 377-383. doi:10.7334/psicothema2013.21

Sicilia, A., \& González-Cutre, D. (2011). Dependence and physical exercise: Spanish validation of the Exercise Dependence ScaleRevised (EDS-R). The Spanish Journal of Psychology, 14(1), 421-431. doi:10.5209/rev_SJOP.2011.v14.n1.38

Standage, M., \& Ryan, R. M. (2012). Self-determination theory and exercise motivation: Facilitating self-regulatory process to support and maintain health and well-being. In G. C. Roberts \& D. C. Treasure (Eds.), Advances in motivation in sport and exercise (pp. 233-270). Champaign, IL: Human Kinetics.

Stephenson, M. T., \& Holbert, R. L. (2003). A Monte Carlo simulation of observable versus latent variable structural 
equation modeling. Communication Research, 30(3), 332-354. doi:10.1177/0093650203252410

Sussman, S., Lisha, N., \& Griffiths, M. D. (2011). Prevalence of the addictions: A problem of the majority or the minority? Evaluation \& the Health Professions, 34(1), 3-56. doi:10.1177/0163278710380124

Sussman, S., \& Sussman, A. N. (2011). Considering the definition of addiction. Environmental Research and Public Health, 8(10), 4025-4038. doi:10.3390/ijerph8104025

Symons Downs, D., Hausenblas, H. A., \& Nigg, C. R. (2004). Factorial validity and psychometric examination of the Exercise Dependence Scale-Revised. Measurement in Physical Education and Exercise Science, 8(4), 183-201. doi:10.1207/ s15327841mpee0804_1

Symons-Downs, D., Savage, J. S., \& DiNallo, J. M. (2013). Selfdetermined to exercise? Leisure-time exercise behavior, exercise motivation, and exercise dependence in youth. Journal of Physical Activity and Health, 10(2), 176-184. doi:10.1123/ jpah.10.2.176

Szabo, A., De la Vega, R., Ruiz-Barquín, R., \& Rivera, O. (2013). Exercise addiction in Spanish athletes: Investigation of the roles of gender, social context and level of involvement. Journal of Behavioral Addictions, 2(4), 249-252. doi:10.1556/JBA.2.2013.4.9

Terry, A., Szabo, A., \& Griffiths, M. (2004). The Exercise Addiction Inventory: A new brief screening tool. Addiction
Research and Theory, 12(5), 489-499. doi:10.1080/ 16066350310001637363

Vallerand, R. J. (2008). On the psychology of passion: In search of what makes people's lives most worth living. Canadian Psychology/Psychologie Canadienne, 49(1), 1-13. doi:10. 1037/0708-5591.49.1.1

Vallerand, R. J. (2010). On passion for life activities: The dualistic model of passion. In M. P. Zanna (Ed.), Advances in experimental social psychology (Vol. 42, pp. 97-193). New York, NY: Academic Press.

Vallerand, R. J. (2012). Passion for sport and exercise: The dualistic model of passion. In G. Roberts \& D. Treasure (Eds.), Advances in motivation in sport and exercise. Champaign, IL: Human Kinetics.

Vallerand, R. J. (2015). The psychology of passion. A dualistic model. Oxford, UK: Oxford University Press.

Vallerand, R. J., Blanchard, C., Mageau, G. A., Koestner, R., Ratelle, C., Léonard, M., Gagne, M., \& Marsolais, J. (2003). Les passions de l'âme: On obsessive and harmonious passion. Journal of Personality and Social Psychology, 85(4), 756-767. doi:10.1037/0022-3514.85.4.756

Vallerand, R. J., \& Verner-Filion, J. (2013). Making people's life most worth living: On the importance of passion for positive psychology. Terapia Psicológica, 31(1), 35-48. doi:10.4067/ S0718-48082013000100004 